\title{
Adult Ileo- Ileal Intussusceptions- A Rare Variety in Intestinal Obstruction
}

\author{
SF KABIR ${ }^{\mathrm{a}}, \mathrm{R}^{\mathrm{AKTER}}{ }^{\mathrm{b}}$
}

\section{Summary :}

Intussusceptions of bowel is more frequent in children but in adult it is less. Generally adult intussusceptions carry the risk of malignancy. So treatment option is not similar with pediatric variety. A female of 40 years was admitted with severe intractable pain, vomiting but no malena. Ultrasonographic

\section{Introduction:}

Adult Intussusceptions is rare but Ileo-Ileal variety is rarer in clinical practice. Although it is common in children. The etiology, clinical presentation of this condition is nonspecific and variable, may cause in delay for specific treatment. Preoperative diagnosis is usually difficult due to nature of presentations. Adult intussusceptions may be recurrent or chronic. The condition is distinct from pediatric intussusceptions in various aspects. In children it is primay and benign, pneumatic or hydrostatic reduction is sufficient in maximum cases. In contrast, adult intussusceptions are secondary to a pathologic condition such as carcinoma, polyp, stricture etc which usually discovered intraoperatively. We present a case report of bizarre presentation without any confirmation before Laparotomy.

\section{Case report:}

A 40 years old female mother of 4 child in Dhaka city, Bangladesh was hospitalized with intractable pain in the abdomen alongwith nausea and vomiting. She had low grade abdominal cramp for about a month. She had no history of bleeding per rectum or mucus in the stool. Past medical history included one caesarian section and bilateral tubal ligation. Patient was treated conservatively in the past as outdoor basis. But due to severity of pain and associated symptoms she got admitted.

a. Dr. Sheikh Firoj Kabir, Assoc. Prof. of Surgery, Tairunessa Memorial Medical College, Tongi, Dhaka, Bangladesh.

b. Dr. Mrs. Rabeya Akther, Senior Consultant, Gyane \& Obs, Mitford Hospital, Dhaka, Bangladesh.

Address of Correspondence: Dr. Sheikh Firoj Kabir, Assoc. Prof. of Surgery, Safe Home: House \# 287, Road \# 7, Flat \# B-5, Dhaka Cantt. Bangladesh. Cell : 01711-807407, E-mail: drfiroj@yahoo.com Received: 7 March, 2013

Accepted: 10 September, 2013 findings and CT scan of abdomen suggested that the lesion could be of bowel origin. After resuscitation the patient was managed surgically and with good outcome.

Key word: Ileum, Intussusceptions, Invagination

(J Banagladesh Coll Phys Surg 2014; 32: 99-101)

Physical examinations showed a pale looking patient with abdominal pain which localized centrally and did not respond to analgesics and spasmodics. Patient was haemodynamically stable with a blood pressure of 130/ $80 \mathrm{~mm}$ of $\mathrm{Hg}$, pulse- 100 beats/minute. She was afebrile. Rectal examinations found nothing abnormality.
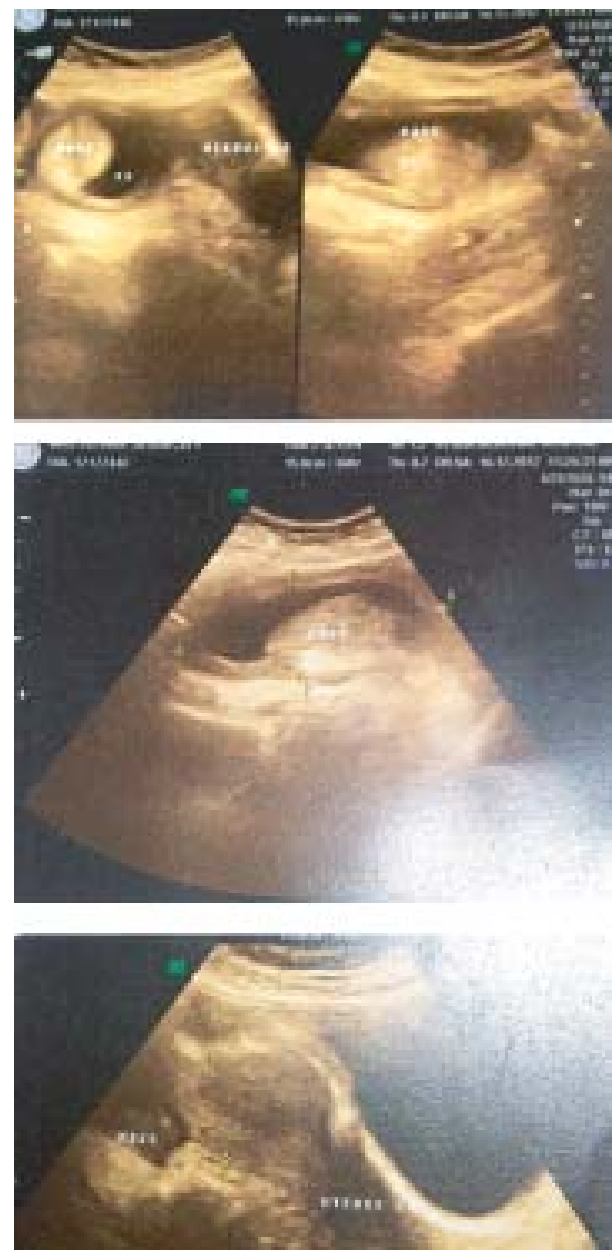

Fig.-1: Ultra Sound Report 
Clinical examinations revealed periumbilical tenderness with hyper peristalsis with no sign of peritonism.

Laboratory test showed a CRP of $0.2 \mathrm{mg} / \mathrm{dl}$, and white cell count of 14000/cumm of blood. Hemoglobin level was $10 \mathrm{gm} / \mathrm{dl}$. Abdominal x-ray shows mesogastic sentinel loops.

Abdominal ultrasound revealed a $5 \times 7 \mathrm{~cm}$ ill defined bowel related mass in the umbilical region with collection in the pouch of doglus (figure-1). CT scan demonstrated an atypical soft tissue mass in the Ileocaecal region with possibility of bowel loops. As the patient had a missed period with abdominal pain and collection in the pouch of doglus a possibility of ectopic pregnancy could not be ruled out.

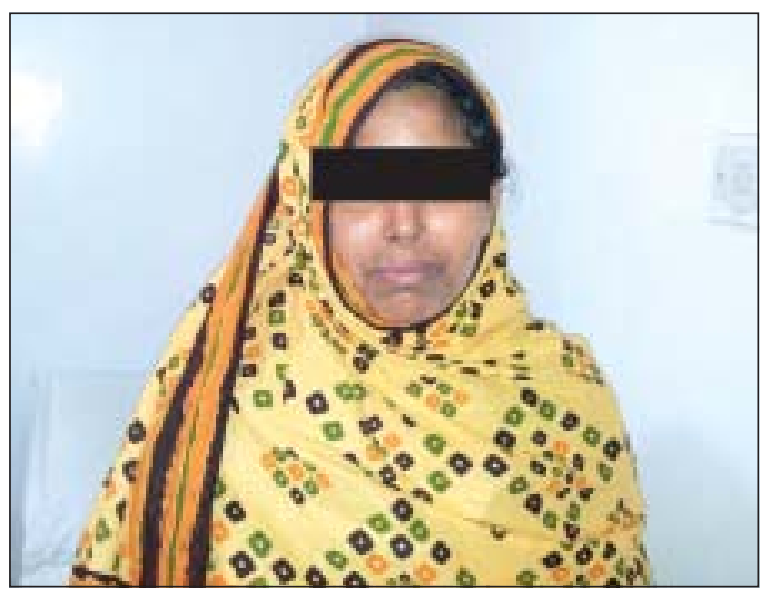

Fig.-2: Photograph of the Patient With Permission

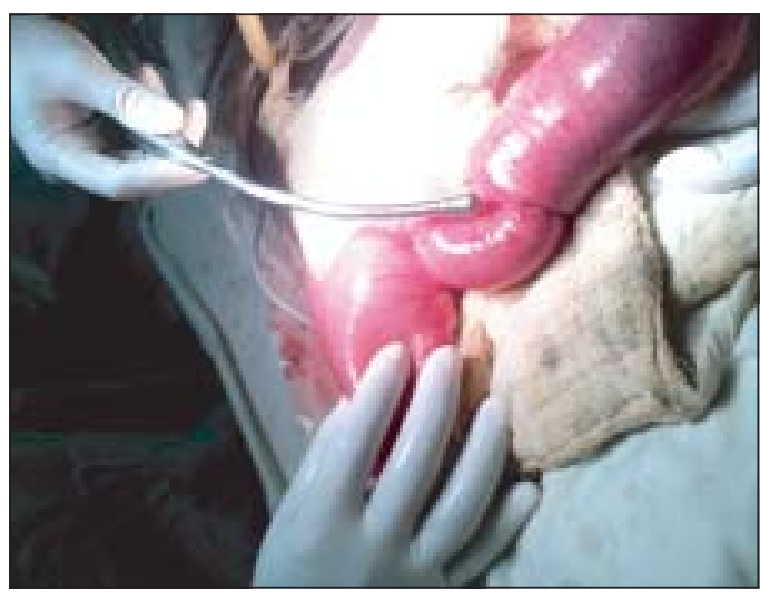

Fig.-3: Ileo- Ileal Intussusceptions

Based on observation laparotomy preformed. It revealed Ileo-Ileal intussusceptions. Partial resection of Ilium done with end to end anastomosis. The specimen was opened and it was an ulcerated lipoma, which protrudes into the Ileum.

Histopathological analysis showed this to be a benign submucosal lipoma. The post operative course was uneventful and the patient was discharged after one week.

\section{Discussion:}

Intussusceptions is an uncommon cause of Intestinal obstruction in adult and more than 95\% cases in the pediatric age group ${ }^{1}$. It is expected to be found in 1/ 30,000 of all hospital admissions, 1/1300 of all abdominal operations ${ }^{2}$. The aetiology, presentation and management of intussusceptions in adults are different from children. In children intussusceptions is usually idiopathic or secondary to a viral illness. However in adults in more than $90 \%$ of cases a cause can be identified causing the intussusceptions ${ }^{3,4}$. This is usually a polyp or a tumour and in majority of cases the colonic tumours are malignant 5,6 .

Intussusceptions leads to the development of venous and lymphatic congestion, resulting in intestinal oedema. If not treated immediately, the arterial blood supply to the bowel will be jeopardized. This can lead to ischaemia, perforation and peritonitis, resulting in a potentially lethal condition ${ }^{7}$.

The clinical presentation is very non-specific which makes this a difficult condition to diagnose. Abdominal pain, nausea, diarrhea and bleeding per rectum are the common symptoms. Rarely this can present with acute intestinal obstruction. The classical triad of abdominal pain, sausage shaped palpable mass and passage of red current jelly stools seen in children is rarely observed in adults 6 ,7. The use of investigations including a barium enema, ultrasound scan, and computed tomography can be helpful to establish the diagnosis ${ }^{7-9}$. CT scan has been reported to have a diagnostic accuracy of around $80 \%{ }^{9}$. The classical finding on a CT scan is a target lesion or target sign which represents the outer intussuscepiens and the inner intussusceptum. The dense intussuscepted mass comprising of swollen bowel and mesentery within the lumen of the bowel is responsible for the characteristic target lesion seen on the CT scan ${ }^{9}$. Ultrasound scan is less invasive and reproducible investigation.

In $90 \%$ of cases a predisposing lesion can be found. This is contrary to intussusceptions in the paediatric 
population, an organic lesion is found in only $10 \%$ of the cases ${ }^{11}$.In adults, it is important to differentiate between small bowel and colonic intussusceptions in $63 \%$ of cases of small bowel intussusceptions a benign underlying lesion can be found, whereas in $58 \%$ of cases of large bowel intussusceptions a malignant aetiology has to be expected ${ }^{12}$. The commonest benign lesion is a lipoma in the colon. These are solitary submucosal lesions with $75 \%$ occurring in the right colon. Small lipomas are asymptomatic. Other benign lesions includes adenomatous polyps and Peutz-Jeghers polyps. However in more than two thirds of cases there is a malignant tumour in the colon or small bowel resulting in intussusception ${ }^{12}$.

Operative treatment is required in all cases of adult Intussusception and unlike children conservative treatment does not work. This usually involves segmental resection. The optimal treatment for adult intussusceptions is slightly controversial. The type of procedure depends upon the location of intussusceptions, pre-operative diagnosis and condition of the intestine at the time of laparotomy. A few authors have described intra-operative reduction of intussusceptions before resection ${ }^{13}$.However most authors do not recommend this due to a higher incidence of malignancy in these cases and hence the risk of tumour embolisation and seedling ${ }^{13}$.

In most cases of adult intussusceptions, primary resection without reduction should be preformed particularly in those more than 60 years of age due to a higher risk of malignancy. In cases of small bowel intussusceptions reduction before resection should be carried out only if there is a pre-operative diagnosis of benign etiology and the bowel is viable.

\section{Conclusion:}

Ileo-Ileal intussusceptions in adult is one of the rare cause of intestinal obstruction. Unlike children, the treatment option almost always surgical. Surgical resection of the intussusceptions without reduction is the preferred treatment in adult as colonic or enteric intussusceptions are associated with malignancy.

\section{References:}

1. Tan KY, Tan SM, Tan AG, Chen CY, Chng HS, Hoe MN: Adult intussusception: experience in Singapore. ANZJ Surg 2003, 73:1044-1047.

2. Dener C, Bozoklu S, Bozokiu A, Ozdemir A: Adult intussusception due to a malignant polyp: a case report. Am Surg 2001, 67(4):35l-3.

3. Van Heel DA, Panos MZ: Colonoscopic appearance and diagno- sis of intussusception due to large bowel lipoma. Endoscopy 1999, 31 (6): 508.

4. Erkan N, Haciyanll M, Yildirlm M, Sayhan H, Vardar E, Polat F: Intus- susception in adults: An unusual and challenging condition for surgeons. Intj Cobrectal D/s 2005. 20:452-56.

5. Dharia KM, Marino AW, Mancini HW: Enterocolic intussuscep- tion in adults. D/s Co/on Rectum 1972, 1 5(3): 194-200.

6. Azar T, Berger DL: Adult intussusception. Annals of Surg 1997, 226:134-8

7. Yalamarthi S, Smith R Adult intussusception: case reports and a review of literature. Postgrad Med J, 2005, 81: 174.177.

8. Eisen LK, Cunningham JD, Aufuses AH Jr: Intussusception in adults: institutional review. JAm Coll Surg 1999, 1 88(4):390-5.

9. Lorenzi M, Iroatulam AJ, Vernillo R, Banducci T, Mancini S, Tiribocchi A, Ferrari FS, Mancini S: Adult colonic intussusception caused by a malignant tumor of the transverse colon. Am Surg 1999, 65(1): 11-4.

10. Pinero A., Riso A., Castellanos G., M. Parrilla P. Intestinal invagination in the adult. Gastro-enterol Hepatol, 1988, 21: 398-400.

11. Begos D. G., Sandor A., Modlin I.M. The diagnosis and management of adult intussusception. Am J Surg, 1997, 173: 88-94.

12. Reinjen HA. Joosten HJ, de Boer HH: Diagnosis and treatment of adult intussusception. Am J Surg 1989, 158: 25-8.

13. Nagorney DM, Sarr MG, Mcilarth DC: Surgical management of intussusception in the adult. Ann Surg 1981, 193:230-6. 